\title{
Faculty Development for the 21st Century: Lessons from the Society of General Internal Medicine-Hartford Collaborative Centers for the Care of Older Adults
}

\author{
Brent C. Williams, MD, MPH, ${ }^{* \dagger}$ Valerie Weber, MD, ${ }^{\ddagger}$ Stewart F. Babbott, MD, ${ }^{\mathcal{S}}$ Lynne M. Kirk, MD, " \\ Mitchell T. Heflin, MD, "Elizabeth O’Toole, MD, " Marilyn M. Schapira, MD, MPH, ** Elizabeth \\ Eckstrom, MD, MPH, ${ }^{\dagger \dagger}$ Asher Tulsky, MD, ${ }^{\ddagger \ddagger}$ Andrew M. Wolf, MD, ${ }^{\mathcal{S}}$ and Seth Landefeld, MD $/ \|$
}

In this review of a recent set of faculty development initiatives to promote geriatrics teaching by general internists, nontraditional strategies to promote sustained change were identified, included enrolling a limited number of "star" faculty, creating ongoing working relationships between faculty, and developing projects for clinical or education program improvement. External funding, although limited, garnered administration support and was associated with changes in individual career trajectories. Activities to enfranchise top leadership were felt essential to sustain change.

Traditional faculty development programs for clinician educators are periodic, seminar-based interventions to enhance teaching and clinical skills. In 2003/04 the Collaborative Centers for Research and Education in the Care of Older Adults were funded by the John A. Hartford Foundation and administered by the Society of General Internal Medicine. Ten academic medical centers received individual grants of $\$ 91,000$, with required cost sharing, to develop collaborations between general internists and geriatricians

From the Divisions of ${ }^{*}$ General Medicine and ${ }^{\dagger}$ Geriatric Medicine, Department of Internal Medicine, Medical School, University of Michigan, Ann Arbor, Michigan; ${ }^{\ddagger}$ Department of General Internal Medicine and Geriatrics, Geisinger Health System, Danville, Pennsylvania; ${ }^{\mathbb{S} D}$ Division of General Medicine and Geriatrics, Baystate Medical Center, Springfield, Massachusetts; "Division of General Internal Medicine and Geriatrics Section, University of Texas Southwestern Medical Center, Dallas, Texas; ${ }^{\top}$ Division of Geriatrics, Department of Medicine, Duke University, Durham, North Carolina; "Division of General Internal Medicine, Case Western Reserve University-MetroHealth, Cleveland, Ohio; ${ }^{* *}$ Division of General Internal Medicine, Medical College of Wisconsin, Milwaukee, Wisconsin; ${ }^{\dagger}$ Division of General Internal Medicine and Geriatrics, Department of Medicine, Oregon Health and Science University, Portland, Oregon; ${ }^{\ddagger \ddagger}$ Division of General Internal Medicine, School of Medicine, University of Pittsburgh, Pittsburgh, Pennsylvania; ${ }^{\S}$ Division of General Medicine, Geriatrics and Palliative Care, Department of Medicine, School of Medicine, University of Virginia, Charlottesville, Virginia; and ${ }^{\| 1}$ Division of Geriatrics, Department of Medicine, University of California at San Francisco, San Francisco, California.

Address correspondence to Brent C. Williams, MD, MPH, 300 N. Ingalls Building, Room 7E18, Ann Arbor, MI 48109. E-mail: bwilliam@umich.edu DOI: $10.1111 / j .1532-5415.2007 .01197 . x$ to create sustained change in geriatrics clinical teaching and learning. Through written and structured telephone surveys, activities designed to foster sustainability at funded sites were identified, and the activities and perceived effects of funding at the 10 funded sites were compared with those of the 11 highest-ranking unfunded sites.

The experience of the Collaborative Centers supports the conclusion that modest, targeted funding can provide the credibility and legitimacy crucial for clinician educators to allocate time and energy in new directions. Key success factors likely include high intensity and duration, integration into career trajectories, integration into clinical programs, and activities to enfranchise institutional leadership. J Am Geriatr Soc 55:941-947, 2007.

Key words: medical faculty; training program; geriatrics; medical education; teaching; internship and residency

$F^{a}$ aculty development programs for clinician educators aim to create sustained change in the targeted skills and behaviors of participants. Although faculty development programs have been shown to improve short-term outcomes in participants, such as attitudes, teaching confidence, and teaching skills, ${ }^{1,2}$ evidence for long-term change in participant behaviors and learner outcomes is limited.

Faculty development for clinician educators is often short term and infrequent, commonly taking the form of an individual or a series of workshops to promote improved teaching skills. ${ }^{3}$ In recent years, other models have been employed that include expanded workshops across multiple sites with central administration or coordination, ${ }^{4,5} 2$ - to 4 -week intensive training programs, ${ }^{6}$ and part-time ${ }^{7,8}$ or full-time ${ }^{9}$ fellowships.

Geriatrics has been recognized as an area of relative deficiency for generalist clinician educators, driven by the aging of the U.S. population and growing numbers of older patients in internal medicine practices. ${ }^{10,11}$ During 2003 and 2004, 10 institutions implemented faculty development 
programs for clinician educators between general internists and geriatricians as a centerpiece of the Collaborative Centers for Research and Education in the Care of Older Adults. The projects were funded by the John A. Hartford Foundation and administered by the Society of General Internal Medicine. Although the participants viewed the projects as innovative and successful, discussions with colleagues and stakeholders revealed that some considered faculty development programs, especially under limited funding, to be a "drop in the ocean" that could bring about few permanent changes in teaching, learner behaviors, or clinical outcomes.

The purpose of this article is to use the experiences of the Collaborative Centers to inform two questions: What features of faculty development programs do educators believe are most likely to foster sustained change in teaching and clinical care in the current academic environment? Is there evidence that relatively small external funding for faculty development programs can foster permanent change in academic careers and local culture?

\section{THE COLLABORATIVE CENTERS FOR GENERAL MEDICINE AND GERIATRICS}

Applicants for Collaborative Centers were required to identify and address barriers to sustained change in geriatrics teaching and clinical care and attempt to modify the cultures of the two divisions at each institution if needed. Institutional matching was required. Forty-three institutions responded to the request for proposals.

Each of the 10 awards consisted of a total of $\$ 91,000$ over 2 years during calendar years 2003 and 2004. Median matching funds were $\$ 125,000$ (range $\$ 105,000-430,000$ ) per institution, largely applied to faculty salary support. Funded centers participated in quarterly conference calls and annual meetings at Society of General Internal Medicine and American Geriatrics Society meetings. Near the conclusion of the funding period, a meeting was held in Dallas, Texas, that included stakeholders in geriatrics and general internal medicine and institutional leaders from each of the 10 centers.

The grant did not mandate program evaluation protocols. Within-site evaluation methods varied and were generally limited to descriptions of teaching activities and short-term changes in attitudes or knowledge in participants. This study was undertaken after the grants were awarded, to derive general lessons across multiple sites.

\section{Data Gathering}

Data were gathered in two waves. First, information was gathered from funded sites to identify common program features designed to foster sustained change. Information sources included the grant proposals, progress reports, and a written survey of program leaders.

In the second wave of data collection, with a goal of recruiting at least 10 unfunded sites, all 10 funded and the 14 highest-ranked unfunded sites were contacted. Three unfunded sites declined to participate, yielding data from all 10 funded and 11 unfunded sites. Information was gathered directly from principal investigators (PIs) at each site. First, to determine the extent to which activities proposed by funded and unfunded sites were accomplished, site PIs reviewed a table listing the objectives from the original applications for funding and identified the degree to which each objective was accomplished as not, partially, or fully accomplished. Also, during a 30- to 60-minute semistructured telephone interview with one of two study authors (BW or VW), PIs were asked to describe programs and faculty activities and collaborations and stories of the career paths of individuals who were the targets of the intervention.

\section{The Collaborative Centers Faculty Development Programs}

\section{Funded Sites - Program Description}

The 10 Collaborative Centers mounted a total of 12 programs to enhance geriatrics teaching and clinical skills among general internists. At each of the two institutions with two programs, one program focused on a small number (2-12) of faculty for more-intense training, whereas a second, briefer program was offered to a larger number $(\geq 20)$ of participants. The median number of faculty participants in the 12 programs was seven (range 1-50).

The structure of the 12 faculty development programs fell along a spectrum with respect to duration and integration with participants' ongoing activities, with one-time workshops or seminars (2 programs) at one end, seminar series with ( 3 programs) or without ( 3 programs) projects outside the seminars in the middle, and project-oriented programs with little or no didactic component (4 programs) at the other end. Activities of project-oriented programs were intended to be incorporated into participants' daily work. The median duration of the seminars at the eight programs in which seminars were a central feature was 16 (range 4-33) hours. In general, there was an inverse relationship between duration of the program and the number of participating faculty.

Three features designed to foster sustained change in clinical teaching were central to at least three programs — star educators, projects, and working partnerships.

\section{Star Educators}

Six programs focused intensely on a small group of general internists for training. Two programs "nested" this small group of star educators in a second layer of faculty development programs for a larger constituency that the star educators assisted in developing. Three programs limited participation to just two to four members, and one program centered on the creation and implementation of clinical and educational innovations by a single faculty member. Limiting the intervention to a small group of faculty was intended to allow each faculty member to receive moreintense training and more fully integrate geriatrics into the long-term career identity and activities of participating faculty.

\section{Projects}

Programs at five institutions prominently featured the completion of specific projects by participants, such as the development of quality improvement programs, curricular revisions and educational materials, and teaching Web sites. Projects were designed to help participants develop skills through application and foster permanent cultural changes 
Table 1. Number and Outcomes of Proposed Objectives from Funded and Unfunded Sites

\begin{tabular}{|c|c|c|c|c|c|c|c|c|}
\hline \multirow[b]{2}{*}{ Funding } & \multirow{2}{*}{$\begin{array}{c}\text { Proposed } \\
\text { Objectives } \\
n\end{array}$} & \multicolumn{3}{|c|}{$\begin{array}{l}\text { Objectives Accomplished } \\
\mathrm{n}(\%)\end{array}$} & \multirow{2}{*}{$\begin{array}{c}\text { Postfunding } \\
\text { Objectives } \\
n\end{array}$} & \multicolumn{3}{|c|}{$\begin{array}{l}\text { Objectives Ongoing After } \\
\text { Funding Period } \mathrm{n}(\%)\end{array}$} \\
\hline & & Not & Partially & Fully & & Not & Partially & Fully \\
\hline \multicolumn{9}{|l|}{ Funded } \\
\hline Education & 78 & $7(8)$ & 25 (32) & $46(59)$ & 70 & $17(24)$ & $23(33)$ & $30(43)$ \\
\hline Research & 34 & $7(21)$ & $7(20)$ & $20(59)$ & 34 & $16(48)$ & $9(26)$ & $9(26)$ \\
\hline Total & 112 & $14(12)$ & $32(21)$ & $66(59)$ & 104 & 33 (32) & $32(30)$ & $39(38)$ \\
\hline \multicolumn{9}{|l|}{ Unfunded } \\
\hline Education & 110 & $92(84)$ & $16(15)$ & $2(2)$ & NA & NA & NA & NA \\
\hline Research & 28 & $22(79)$ & $2(7)$ & $4(14)$ & NA & NA & NA & NA \\
\hline Total & 138 & $114(83)$ & $18(13)$ & $6(4)$ & NA & NA & NA & NA \\
\hline
\end{tabular}

$\mathrm{NA}=$ not applicable.

by increasing the visibility of geriatrics-related topics and clinical care.

\section{Partnerships}

Three programs explicitly created one-on-one general internist-geriatrician partnership pairs to work on projects or as mentoring relationships. It was hoped that one-on-one pairings would foster working relationships across divisions that would persist after the program ended.

\section{Comparison of Funded and Unfunded Sites Accomplishment of Objectives}

Funded sites accomplished a far larger proportion of proposal objectives than unfunded sites (Table 1). For example, of the 78 educational initiatives at funded sites, $91 \%$ were rated as fully $(59 \%)$ or partially $(32 \%)$ accomplished during the 2 -year period of the grant, compared with $17 \%$ (of 110) proposed educational initiatives at unfunded sites. With one exception (Institution R, Table 2), when initiatives at unfunded sites were accomplished, it was due to a subsequent successful proposal for external funding. Only four of the 11 unfunded sites achieved alternative funding.

\section{Program Initiatives}

Funded sites all implemented discrete, identifiable faculty development programs (Table 2). For example, several funded centers established ongoing new or expanded geriatric education programs within the internal medicine residency.

At several centers (e.g., Institutions B, C, D, and H), general internist clinician educators became known for teaching geriatrics to generalists. These faculty members have created further faculty development activities and disseminated educational products (e.g., Web sites and seminars) inside and outside their institutions. At Institution F, the star educator flourished in the role. As a result of her increased visibility as an educator she is now coleader of the house staff training program and maintains her geriatrics focus. At Institution A, three of four star educators are pursuing careers focused on geriatrics education.

At unfunded sites, discrete educational and research initiatives proposed but not implemented included an integrated general internal medicine-geriatrics fellowship program, a Web-based distance learning program for com- munity generalists, a multidisciplinary geriatric assessment clinic for frail older people jointly staffed by general internal medicine and geriatrics faculty, and pilot research projects in aging. A common theme was the inability to expand and integrate geriatrics teaching into the internal medicine residency program through faculty training and curriculum reform.

After being asked to re-read their proposals in preparation for the interviews, many PIs from unfunded sites commented that there was a sense of "opportunity lost." Only two of the 11 sites were able to obtain additional funding for their envisioned programs. Although the process of responding to the request for proposals created some new collaborations, few were sustained. "There were a lot of new ideas stimulated, which did not come to fruition," one division chief commented. At Institution P, where the collaboration between general internal medicine and geriatrics had never been strong, a working group was convened, but when the funding did not occur, all activity stopped. Comments that capture this common sentiment are:

"The money really does matter. This was an opportunity for an important educational collaborative that was lost. This [funding] had the potential to plant a seed and grow in a place where geriatrics and general internal medicine separately are very strong and would have been an opportunity to link the divisions and create some synergy where none currently exists."

"We were a model program for the combined geriatrics/ general internal medicine model at one time, but the divisions then split. This funding would have provided an important "band-aid" to form a connection between the divisions on educational, clinical, and research efforts. At this point, we remain farther apart then ever."

A few PIs felt that the effect of not obtaining the funding was not merely a lost opportunity, but may have had a deleterious effect on geriatrics initiatives. As one PI stated:

"People are so busy and geographically dispersed at different locations that it is impossible to do these kinds of activities without funding. Clinicians have more demands placed upon them than ever. The focus has now shifted to developing a hospitalist program. I think geriatrics would have continued to maintain a higher profile had we received the funding." 
Table 2. Characteristics and Major Proposed Initiatives of Highest-Ranked Institutions Responding to Hartford 2002 Request for Proposals "Collaborative Centers for Research and Education in the Care of Older Adults"

\begin{tabular}{llll}
\hline Institution & Characteristics of Institution & Major Proposed Initiatives & Key Findings \\
\hline
\end{tabular}

Funded

A Teaching hospital affiliated with a Implement Geriatric Medicine major academic medical center. Faculty Track with didactic and Large clinical and teaching Division experiential components to train of General Medicine.

B Rural integrated healthcare delivery system with strong GIM division, new geriatrics section within GIM. Single fellowshiptrained geriatrician on faculty.

C Large academic urban medical center. Large general medicine and geriatrics divisions. Existing education and research training programs for general medicine faculty.

D Urban academic medical center. Some ongoing activities in general medicine faculty development.

E Academic medical center with combined sections of general medicine and geriatrics but little collaboration.

F Large, academic institution, welldeveloped geriatrics and general medicine divisions. Little integration of strong divisions of general medicine and geriatrics.

Academic medical center with strong general medicine and geriatrics divisions, moderate collaborations in research, less so in education.

$\mathrm{H} \quad$ Academic medical center, strong general medicine and geriatrics divisions with history of moderate collaborative efforts.

I Urban GIM division with new geriatrics section, previous section within family practice division.

$\mathrm{J}$ Academic, multicenter, poor integration of large general medicine and small geriatrics division

Recruit and train general research at three progressive levels of intensity.

Complete needs assessment for faculty, implement geriatrics faculty development course, Develop skills and career focus of a general internist to develop and teaching program in residency related to geriatrics. General medicine-geriatrics faculty pairs develop and deliver faculty; development of Webbased learning modules. Joint research seminars, pilot aging research projects.

Aging collaborative research projects; generalist faculty collaboratives around women's health and aging, faculty development in geriatrics; collaborative research projects. Resident firm evaluative project to revise new geriatric curricular approaches; Web-based educational programs. faculty. Joint research projects between general medicine and
Grant provided high visibility and launched new money and integration of the hospital and principal investigator into medical school activities. Three of four faculty scholars pursuing geriatrics-related careers. Limited success in implementing research goals. Ten geriatrics scholars, 90 rural community generalists trained, geriatric curriculum integrated into internal medicine residency program, support for an aging outcomes research institute, growth of geriatric clinical programs. medicine faculty for teaching and

Trained seven general medicine teachers in geriatrics at first level. Additional cohorts trained after funding ended. Peer partnership program continues. Establishing an infrastructure (e.g., precedent for training sessions, e-mail discussion list) allows rejuvenation of same after grant with little incremental effort. provide pilot funding for research. a combined clinical improvement Created ongoing faculty development program in geriatrics for new faculty and geriatrics fellows. No applicants for pilot research funding.

Through a highly visible quality improvement initiative, more teaching on geriatric topics by general medicine and geriatrics faculty. For the first time ever, two residents entered geriatrics fellowships.

Key geriatrician clinician educators supported, including one star educator promoted to case-based seminars to generalist associate program director; leveraged development program in geriatrics faculty.

to create lead clinician educators.

Generalist-geriatrics educational Two strong lead geriatrics clinician educators development programs, CD-ROM

Star Clinician-Educators in Aging form teams, training of generalist geriatrics. projects into larger awards including more than \$2 million of additional funding to support research and educational projects.

Twenty faculty trained in geriatrics; numerous publications and grant proposals among junior Two strong lead geriatrics clinician
produced, national dissemination of educational projects, ongoing funding, National Institute on Aging career development award.

Important follow-up funding, including from a Geriatrics Academic Career Award, Aetna Foundation, and the Bureau of Health Professions, with growth of clinical programs at institution such as an Acute Care of the Elderly unit. Chair supported three new geriatrics faculty positions. National presentations.

Twelve Star educators trained 60 generalist faculty. Key generalist faculty member left position to embark on geriatrics fellowship to return to institution to lead geriatrics program. 
Table 2. (Contd.)

\begin{tabular}{cl}
\hline Institution & \multicolumn{1}{c}{ Characteristics of Institution } \\
\hline $\begin{array}{c}\text { Unfunded } \\
\text { K }\end{array}$ & $\begin{array}{l}\text { Large urban academic institution. } \\
\text { Geriatrics faculty spend little time } \\
\text { at major teaching hospital. }\end{array}$ \\
L & $\begin{array}{l}\text { Large urban academic institution } \\
\text { with general medicine division } \\
\text { oriented toward health services } \\
\text { research and some collaborations } \\
\text { with geriatrics. Few connections in } \\
\text { education. } \\
\text { Large urban academic institution. }\end{array}$
\end{tabular}

$\mathrm{N} \quad$ Large urban academic institution with large geriatrics and general medicine divisions without much collaboration.

O Mid-sized academic institution with clinical and teaching focus in general medicine and relatively large, physically separate geriatrics division operating under a large geriatrics education grant.

P Academic medical center with large general medicine division, small geriatrics division, little collaboration.

Q Newly integrated general medicine and geriatrics division at academic medical center.

R Urban community teaching hospital, integrated general medicine and geriatrics division.

S Academic medical center, separate divisions of general medicine and geriatrics with little collaboration.

$\mathrm{T} \quad$ Large academic institution, welldeveloped but separate geriatrics and general medicine divisions.

U Academic medical center with strong general medicine and geriatrics division, strong but separate and geographically dispersed educational and research programs.

Major Proposed Initiatives

Key Findings

Train two generalist physicians as teachers and clinicians with geriatrics focus and two as researchers in geriatrics.

New collaborative research projects proposed, and geriatric content was to be integrated into existing educational venues.

One junior faculty to undergo training in geriatrics-oriented research and education and implement research and education programs.

Develop outpatient curriculum and evidence-based seminars in geriatrics for faculty. Support pilot collaborative research projects.

Geriatrics clinical, teaching, and research training seminars for generalist faculty and expanded geriatrics teaching in internal medicine residency.

General medicine and geriatrics faculty precepting teams for new frail elder continuity clinic experience, faculty development programs in geriatrics, and health services research.

Train the trainer faculty development of generalists in geriatrics core competencies, research faculty development program.

Develop a core of generalist faculty to teach geriatric content to internal medicine residents, including Web based.

Jointly staffed geriatric-generalist clinic for frail and complex older people; three aging research pilot projects.

Faculty development in education and research in aging for general medicine and geriatrics fellows; establish formal research mentorships in aging research. Combined general medicinegeriatrics fellowship, combined activities for geriatrics and general medicine fellows.
Under subsequent successful training grant based on Collaborative Centers application, two physician educators were trained.

None of the proposed activities happened and have not been revisited since the time of the proposal.

Faculty member subsequently received funding to accomplish the proposed activities. "Without the (subsequent funding) not much would have happened."

Education proposals did not happen.

Research portions of the proposal have moved forward with new funding.

Proposed initiatives not accomplished.

When funding was not received collaborative efforts were not discussed further.

Initial relationships formed in developing proposal not sustained. Leadership unaware of other funding streams for such projects.

No subsequent funding obtained, although organization able to partner with teaching institution to grow geriatric education.

No funding for collaborative efforts; got diverted into other areas, mainly clinical and hospitalist.

No continued collaborations, institution was able to obtain Health Resources and Services Administration and Reynolds funding to train geriatrics clinician educators but not a collaborative project.

New collaborations were formed in pulling together proposal but ceased when funding not received. Looked but unable to find alternative funding arrangements. 
Other PIs felt that geriatrics has expanded at their institutions but did not include collaborations with general medicine. For example, one small institution has begun a fellowship training program in geriatrics, yet at that institution, "cultural issues and tensions exist due to the siloing of generalism and geriatrics at our institution, which could have been addressed in advance of beginning the fellowship program to create a more collaborative environment."

\section{Career Stories}

Careers were substantially affected during the funding period, in the view of the PIs. For example, two generalist faculty trained in geriatrics under the Collaborative Centers have entered full-time geriatrics fellowships, at fellows' salaries, as part of a change in career focus to geriatrics. Another has received additional intensive training in geriatrics at an outside institution. At Institution E, two residents from a class affected by the funded project chose to enter geriatrics, whereas no previous residents had done so.

Most site directors from funded sites gave examples of presentations by participating junior faculty at national meetings and of faculty with expanded commitments to education and research in aging.

At a few unfunded sites, careers were overtly redirected toward nongeriatrics domains in the absence of funding. At Institution O, the PI put it succinctly: "[Without the Collaborative Centers funding], research careers have moved on [outside geriatrics] or not moved on.”

\section{Institutional Culture/General Internal Medicine and Geriatrics Collaboration}

Several funded institutions commented on the value of site visits and the national conference in Dallas in influencing decision-makers at their organization. As one PI commented: "The meeting in Dallas was attended by the Chair of Medicine. He came back very energized, having had the opportunity to see people across the country from various institutions who valued geriatrics and seeing that we were a part of that. That was no small thing."

The PI from Center J commented on the overall effects of the funding on the practice and teaching culture at her institution: "Our faculty have loads of confidence about teaching geriatrics that they did not have before this project. ... Geriatrics is much more on the radar screen now and will have sustainability over time."

\section{Implications}

The Collaborative Centers' experience suggests that innovative approaches to faculty development may be implemented with limited resources. The comparison with unfunded sites provides qualitative evidence that small amounts of external funding with cost sharing can bring about changes in practice, teaching, and research that involved faculty perceived to be substantial. The findings were similar across programs of varying size and structure. Although the results reported here are subject to reporting bias, the contrast between responses of funded and unfunded sites, and the uniformity of responses within each group, were striking. Several themes in particular emerged.

\section{Program Design: Broader Context, More Comprehensive Strategy}

Faculty development programs for clinician educators have traditionally consisted of brief seminars in teaching skills, with or without simultaneous enhancement of clinical skills, ${ }^{12,13}$ although experts have argued that faculty development should be understood more broadly as part of an ongoing, comprehensive strategy. ${ }^{14-16}$ This sentiment is captured in describing faculty development as "efforts designed to facilitate faculty members' commitment to and ability to achieve both their own goals and their institution's goals."17

The innovations introduced by the Collaborative Centers may be viewed as movement away from traditional stand-alone seminars toward fuller integration with institutional goals and daily activities of the faculty. At most (6/10) funded institutions, program objectives included skills in educational program leadership and organizational change in addition to clinical and teaching skills. This movement is apparent in each of the three common program strategies highlighted here: focusing on a limited number of "star educator" faculty who could become local advocates and role models for the new content and skills, the use of educational projects to foster new working relationships and permanent changes in the process of care and teaching, and the development of new one-on-one working partnerships between faculty across disciplines. However, even with these innovative approaches to sustained change, all program leaders at funded sites expressed concern about the durability of the changes. The most often-cited concern focused on institutional pressures for clinical productivity in competing for faculty time to maintain, revise, or expand activities begun under the program.

Most obviously, the difficulty in sustaining the effects of faculty development programs relates to the fact that good teaching is only indirectly related to revenue, unlike clinical or research activities. Because it is unlikely that good teaching will be directly related to institutional revenue in the foreseeable future, alternative models for improving and maintaining good teaching should be sought. Two such models are a regulatory model, in which teaching skills are regularly updated, analogous to clinical skills improvement through Continuing Medical Education, and a quality model, in which teaching institutions compete for applicants based on valid measures of teaching quality in their programs. These and other models should be examined and tested in future faculty development programs.

\section{Readiness for Change}

A key characteristic common in applicant organizations, as evidenced by the preparation and submission of applications for grant funding, is that they were interested and ready for change. Opportunities were perceived to exist in education, especially, for general internists to develop new knowledge and skills related to care and teaching about older patients. Other institutional characteristics, such as size, setting, and patient population, appeared less important in influencing the focus or success of funded programs. Perhaps self-evident, this fact nonetheless speaks to the importance of meeting local needs in funding faculty development programs. 


\section{Legitimacy and Measurable Resources as Means of Change}

A recurring theme at the Collaborative Centers and their unfunded counterparts was that small amounts of funding were necessary and sufficient to implement intended reforms. It is possible that receipt of a measurable resource from an outside, respected source provides legitimacy and credibility to new programs and new activities and helps to offset opportunity costs from other activities (usually billable clinical care). Ideally, these new activities (e.g., new rotations, new types and settings for teaching) then become perpetuated through integration into routine practices.

\section{Fostering Cultural Change}

"Culture," as used here, means the shared, implicit knowledge, attitudes, and beliefs of a group of faculty and leaders who work together. The common perception at funded sites that funding facilitated cultural change essential to further growth in geriatrics-related education and research was intriguing. Essential cultural change as discussed by the interviewees occurred (or did not occur) at two levels: faculty and leadership.

At the faculty level, many programs fostered the creation of new, often informal, working relationships between faculty. Critical to these relationships appeared to be the adoption of common attitudes, values, knowledge, and language regarding the care of older persons, which in turn allowed faculty to work to solve commonly perceived problems, although without support and shared belief in the importance of the program by local leaders (deans, department chairs, division heads, and program directors), sizable or lasting effects were rare. From the point of view of the program leaders, key mechanisms for enfranchising local leaders included involving them in site visits and garnering their participation at a national meeting, where they interacted with and heard from funders, government officials, and counterparts at other institutions. The net effect was to create a framework for discussion and a common set of objectives, legitimated and made credible by respected individuals and organizations.

The conditions and mechanisms for change suggested by these findings may provide important guidance for $\mathrm{fu}$ ture efforts to facilitate faculty development with small grants. Strategies most likely to succeed in future faculty development initiatives in geriatrics education and research should include providing adequate resources to provide credibility and protected time for faculty to channel time and effort in new directions, fostering new working relationships and programs likely to become routine, and enfranchising local leadership through site visits, networking, and external recognition of program accomplishments.

\section{ACKNOWLEDGMENTS}

The authors wish to thank Judy Bowen for contributing to the concepts described in the paper, Nancy Woolard for assisting with communication between the Collaborative Centers, and the project leaders and faculty participants at the Collaborative Centers for their support and contributions to the project.

Financial Disclosure: Supported by the John A. Hartford Foundation and the Society of General Internal Medicine.

Author Contributions: Brent C. Williams, Valerie Weber, and Stewart Babbott designed most features of the study. All authors contributed to the final design. All authors contributed to the acquisition of data. Brent C. Williams, Valerie Weber, and Stewart Babbott analyzed and interpreted the data. All authors made substantive contributions to the text.

Sponsor's Role: The sponsor had no role in the design, methods, data collection, analysis, or preparation of the manuscript.

\section{REFERENCES}

1. Skeff KM, Stratos GA, Bergen MR et al. Regional teaching improvement programs for community-based teachers. Am J Med 1999;106:76-80.

2. Dennick R. Teaching medical educators to teach. The structure and participant evaluation of the Teaching Improvement Project. Med Teacher 1998;20: 598-601.

3. Gruppen LD, Frohna AZ, Anderson RM et al. Faculty development for educational leadership and scholarship. Acad Med 2003;78:137-141.

4. Quirk ME, DeWitt T, Lasser D et al. Evaluation of primary care futures: A faculty development program for community health center preceptors. Acad Med 1998;73:705-707.

5. Crist TB, Clayton CP. Generalist faculty teaching in community-based settings: An interim report on the General Internal Medicine Faculty Development Project. Am J Med 2001;111:588-592.

6. Skeff KM, Stratos GA, Berman J et al. Improving clinical teaching. Evaluation of a national dissemination program. Arch Intern Med 1992;152: 1156-1161.

7. Eleazer GP, Laditka SB, Roberts E et al. Geriatrics training and education for nongeriatrician faculty: The Dean's Faculty Scholars in Aging Program. J Am Geriatr Soc 2005;53:1806-1810.

8. Steinert Y, Nasamith L, McLeaod PJ et al. A teaching scholars program to develop leaders in medical education. Acad Med 2003;78:142-149.

9. Robbins LJ. Mid-career faculty development awards in geriatrics: Does retraining work? J Am Geriatr Soc 1993;41:570-571.

10. Landefeld CS, Callahan CM, Woolard N. General internal medicine and geriatrics: Building a foundation to improve the training of general internists in the care of older adults. Ann Intern Med 2003;139:609-614.

11. Rubin CD, Stieglitz H, Vicioso B et al. Development of geriatrics-oriented faculty in general internal medicine. Ann Intern Med 2003;139:615-620.

12. Skeff KM, Stratos GA, Mygdal W et al. Faculty development: A resource for clinical teachers. J Gen Intern Med 1997;12:S58-S63.

13. Clark JM, Houston TK, Kolodner K et al. Teaching the teachers. National survey of faculty development in departments of medicine of U.S. teaching hospitals. J Gen Intern Med 2004;19:205-214.

14. Irby DM. Faculty development and academic vitality. Acad Med 1993;68:760-763.

15. Hesketh EA, Bagnall G, Buckley EG et al. A framework for developing excellence as a clinical educator. Med Educ 2001;35:555-564.

16. Bland CJ, Wersal L, VanLoy W et al. Evaluating faculty performance: A systematically designed and assessed approach. Acad Med 2002;77: 15-30.

17. Bland CJ, Seaquist E, Pacala JT et al. One school's strategy to assess and improve the vitality of its faculty. Acad Med 2002;77:368-376. 